\title{
Spectrophotometric study of complexation between a series of salophens and some transition metal ions in DMF solvent
}

\author{
Ardeshir Shokrollahia,*, Mehrourang Ghaedia, Sara Alipourb and Ali Hossein Kianfara \\ a Department of Chemistry, Faculty of Sciences, Yasouj University, Yasouj, 75918-74831, Iran \\ b University of Applied Science and Technology, Pasargad Branch, Saadatshahr, 73741-173, Iran \\ *Corresponding author at: Department of Chemistry, Faculty of Sciences, Yasouj University, Yasouj, 75918-74831, Iran. Tel.: +98.741.2223048; \\ fax: +98.741.2223048. E-mail address: ashokrollahi@mail.yu.ac.ir (A. Shokrollahi).
}

\section{ARTICLE INFORMATION}

Received: 04 September 2010

Received in revised form: 12 November 2011

Accepted: 08 December 2011

Online: 30 September 2011

\section{KEYWORDS}

Complexation

Salophen's derivatives

DMF

Spectrophotometric study

KINFIT program

Metal ions

\section{Introduction}

The ligands have an important role as reagents in analytical chemistry for preconcentration, speciation and determination of elements in real samples [1-3]. Nowadays, considerable attention has been paid to the Schiff bases and their metal complexes. Aromatic Schiff bases or their metal complexes catalyze reactions on oxygenation [4], hydrolysis [5], electroreduction and decomposition [6]. Some of Schiff base derivatives or their metal complexes show antibacterial activity against Escherichia coli, Staphylococcus aureus, Bacillus subtilis, and Proteus vulgaris pathogenic bacteria [7,8], possess effective antifungal [9], anti-HIVactivity [10] and antiviral activity [11].

A class of these compounds has shown growth inhibitory activity with seedling of wheat, rye and barley [12]. Several Schiff bases are known to possess anti-inflammatory allergy reducing activity, radical scavenging, analgesic and antioxidative activity [13,14]. Additionally, some of these compounds possess antiulcer activity [15] and may also alter reproductive physiology [16].

Azomethine complexes Schiff base dyes, give fast colors to leathers, food packages, wools etc. [17]. Novel tetra dentate Schiff base acts as a chromogenic reagent for determination of metal ions such as $\mathrm{Ni}^{2+}$ ion in some natural food samples [18].

In recent years Schiff base compounds have been a famous and applicable class of reagents in analytical fields, such as potentiometric sensor [19-21], bulk and supported liquid membrane transport [22,23], optical sensor [24], solid phase and cloud point extraction $[25,26]$. The study of complexation reaction of these ligands in nonaqueous matrices could be used as an efficient strategy to design the analytical systems. Thus, thermodynamic studies of complexation reaction of these compounds with metal ions lead to a better understanding of the high selectivity of these ligands toward different metal cations. Our group has used the kinfit $[27,28]$ and best program [29], for evaluating the stability constant of complexes between several ligands, transition and heavy metal ions using the spectrophotometric and potentiometric data [30-35]. These Ligands include pyridine carboxylic acids, pyridine amines, oximes, and especially Schiff bases as an interesting molecule group not only in coordination but in analytical chemistry.

In this study we spectrophotometrically investigated and the effects of the ligands structure on the stability constants of the complexation of some transition and heavy metal ions with salophen and few of it's derivatives. Based on the results of this study, one analyst can select the suitable Ligands for analytical aims, and one inorganic or organic researcher can focus to synthesize new ligands with proper characterizes toward cations for the selective and sensitive determination of the proposed metal ions.

\section{Experimental}

\subsection{Reagents}

Analytical grade nitrate salts of $\mathrm{Cu}(\mathrm{II}), \mathrm{Ni}(\mathrm{II}), \mathrm{Co}(\mathrm{II}), \mathrm{Cd}(\mathrm{II})$, $\mathrm{La}(\mathrm{III}), \mathrm{Ce}(\mathrm{III})$ and $\mathrm{Zn}(\mathrm{II})$ ions are purchased from Merck, Dermasdat, Germany and used without any further purification. The ligands 3-MeO salophen $\left(\mathrm{L}^{1}\right)$, 4- $\mathrm{MeO}$ Salophen $\left(\mathrm{L}^{2}\right), 5-\mathrm{MeO}$ Salophen $\left(\mathrm{L}^{3}\right), 5-\mathrm{Br}$ Salophen $\left(\mathrm{L}^{4}\right)$, and $5-\mathrm{NO}_{2}$ Salophen $\left(\mathrm{L}^{5}\right)$ were synthesized in our laboratory by reaction of 1,2phenylene diamine and salicylaldehyde derivatives in methanol, the details of synthesis was reported in our previous paper [36]. The ligand structures and their wavelengths were summarized in Table 1. Tetraethylammonium perchlorate (TEAP) was synthesized according to literature [37]. 


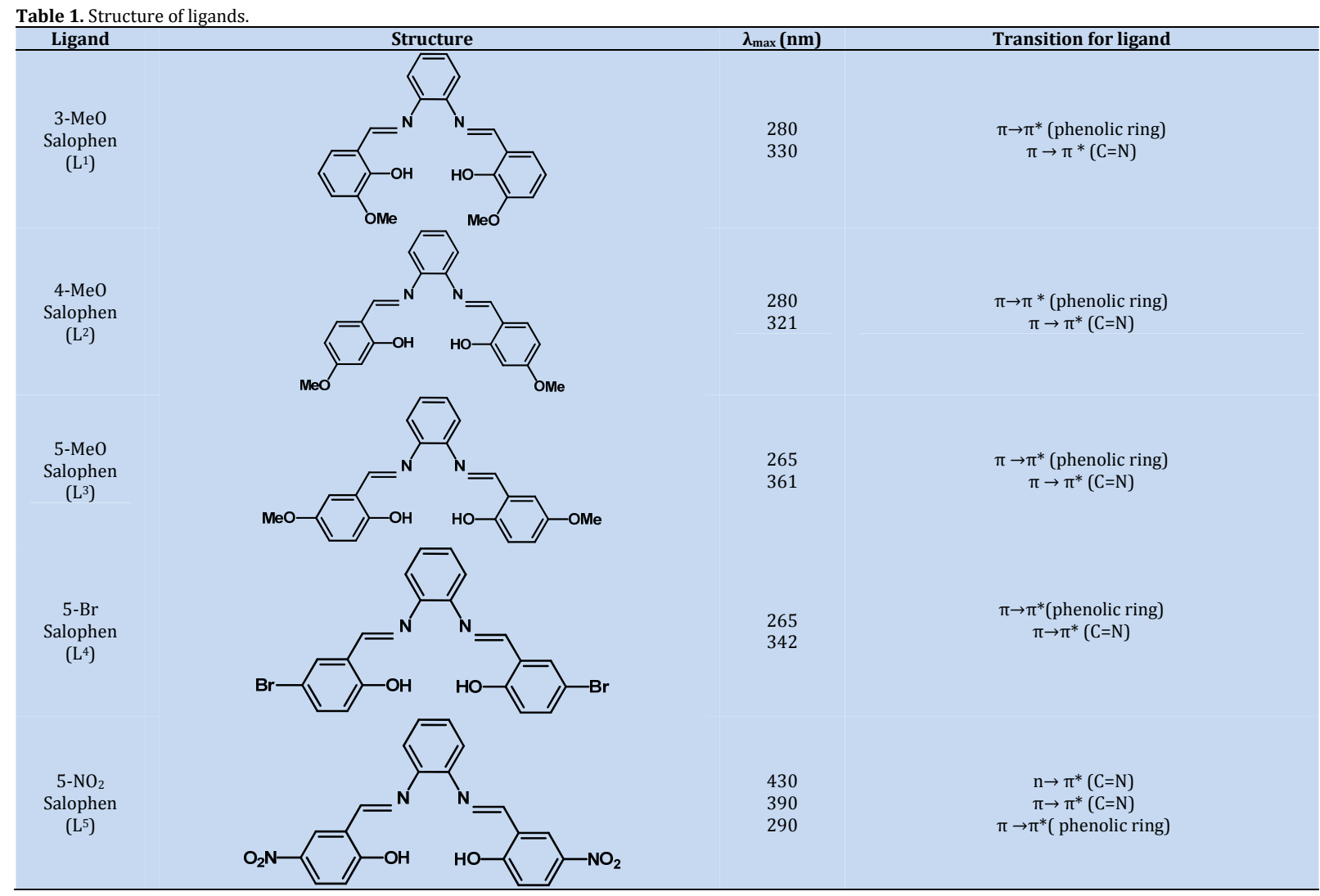

\subsection{Instrumentation}

Absorbance measurements were carried out with a Perkin Elemer model Lambda5 spectrophotometer (Nordrhein, Westfalen, Germany).

\subsection{Spectrophotometric titration}

Standard stock solutions of ligands $\left(1.0 \times 10^{-3} \mathrm{M}\right)$ and the metal ions $\left(1.0 \times 10^{-3} \mathrm{M}\right)$ were prepared by dissolving appropriate and exactly weighed (with an accuracy of \pm 0.0001 g) amount of pure solid compounds in pre-calibrated $25.0 \mathrm{~mL}$ volumetric flasks and diluted to the mark with DMF. Working solutions were prepared by appropriate dilution of the stock solutions. According to the spectra reported (Figures 1-4), titration of the ligand solution (for typical $3.8 \times 10^{-5} \mathrm{M}, 2.6 \mathrm{~mL}$ ) was carried out by the addition of micro-liter amounts of a concentrated standard solution of the metal ion $\left(1.0 \times 10^{-3} \mathrm{M}\right)$ using a pre-calibrated micro-syringe, followed by absorbance intensity reading at $25.0{ }^{\circ} \mathrm{C}$ and $0.05 \mathrm{M} \mathrm{TEAP}$, and the spectrum was recorded.

\section{Results and discussion}

The complexation of few transition metal ions with some ligands including $\mathrm{L}^{1}, \mathrm{~L}^{2}, \mathrm{~L}^{3}, \mathrm{~L}^{4}$ and $\mathrm{L}^{5}$ have been investigated spectrophotometrically and their stability constants using KINFIT program has been evaluated.

The aim of comparative studies of the various equilibrium processes in virtually all cases is to find a correlation between the values of the equilibrium constants and the parameters reflecting the chemical properties of the components participating in the process. Basically two types of the parameters reflecting the chemical properties are distinguished: (a) physical parameters due to the interaction of the component in question with physical fields (e.g. ionization potential, electro affinity, ionic potential, polarizibility) and (b) correlation coefficients expressing the connection between the various chemical properties, which can be determined from a large number of studies (e.g. Hammet $\sigma$ value, electronegativity, data reflecting the hard-soft nature, etc.). Also, the stability of a transition metal complex with a polydentate chelate ligand depends on the other factors including: number and type of the donor atoms present and the number and size of the chelate rings formed on complexation [38]. In addition, the stability and selectivity of complexation strongly depend on the donor ability, dielectric constant [39], shape and size of the solvent molecules [40].

The donor ability of Schiff bases to metal ions depended on type and position of functional groups to phenolic oxygen. In general, during the complexation of tetra dentate Schiff base ligands with metal ions, two internal hydrogen bonds are broken, two M-N and two M-O bonds corresponding to iminic nitrogen and phenolic oxygen are formed. It is clear that the formation constants depended on the power of hydrogen bonding between the phenolic hydrogens and iminic nitrogens. The hydrogen bond in this type of Schiff bases depended on functional groups such as $-\mathrm{NO}_{2}$ and $\mathrm{MeO}$ on the aldehyde and amine parts of the ligands. For example, in the complexes the $\mathrm{MeO}$ substituted group increases donorability of Schiff base, while $\mathrm{NO}_{2}$ group decreases it.

On the other hand, the functional group $\mathrm{NO}_{2}$ increases the acidity of $\mathrm{OH}$ group therefore it increases the formation constant value while the $\mathrm{MeO}$ functional group has a reverse effect. The observed results can be due to these paradox effects. 

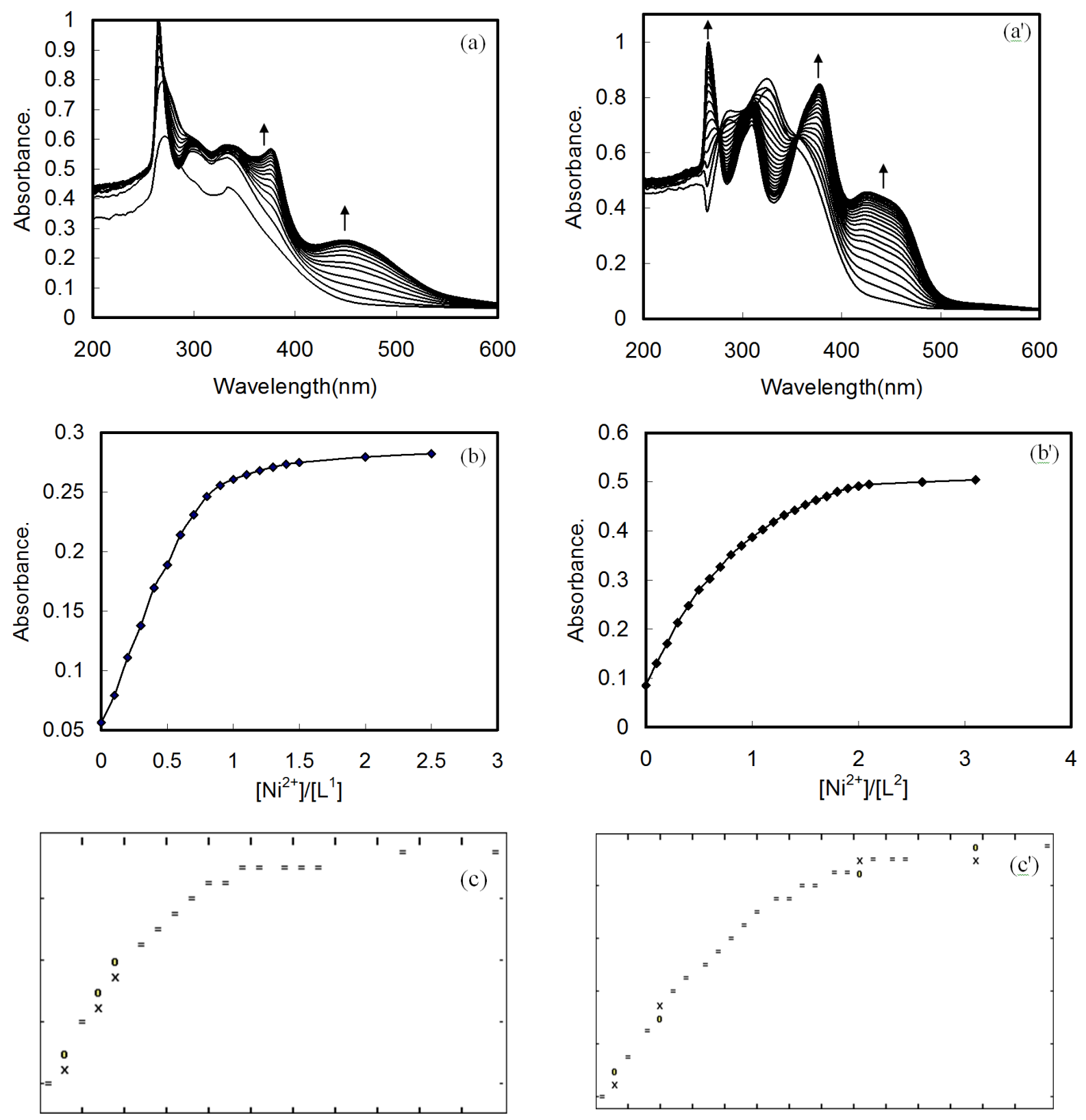

Figure 1. UV-Vis spectra for titration of $\mathrm{L}^{1}\left(3.51 \times 10^{-5} \mathrm{M}\right)(\mathrm{a})$ and $\mathrm{L}^{2}\left(3.46 \times 10^{-5} \mathrm{M}\right)(\mathrm{a})$ with $\mathrm{Ni}^{2+}$ ion in $\mathrm{DMF}\left(\mathrm{T}=25{ }^{\circ} \mathrm{C}, \mathrm{I}=0.05 \mathrm{M}\right.$ and $0.05 \mathrm{M}$ TEAP) and the corresponding absorbtion mole ratio plots at $451,450 \mathrm{~nm}$, respectively (b, b') and corresponding curve fitting (c, $\left.\mathrm{c}^{\prime}\right)$.

Addition of metal ions to the ligand solution cause appearance of new or shifted peaks (red shift) in the spectrum due to the coordination of metal ions with imines nitrogen and phenolic oxygen [41] and lead to formation of ML, ML2 or $\mathrm{M}_{2} \mathrm{~L}$ [42-45]. The isosbestic points can predict the numbers of equations in solution.

As it is shown typically in Figure $3 b$, an increase in the concentration of transition metal ions makes one of the original peaks of the Schiff base ligand at about $350 \mathrm{~nm}$ gradually vanished. The other original peak or shoulder shifted to higher wavelengths about $390 \mathrm{~nm}$ with an increase in its intensity and a new peak appeared at about $500 \mathrm{~nm}$ with an increase in intensity. Generally, the bonds with lowest energies in the spectra of the ligand was assigned to $n \rightarrow \pi^{*}$ transition of the imine nitrogen atoms in conjugation with the phenol groups which are eliminated after coordination with metal ion. The absorption bands with highest energies were assigned to $\pi \rightarrow \pi^{*}$ of benzene or phnolic rings of the ligands that may shift to higher energies after coordination. The bonds between these transitions were suggested to be related to $\pi \rightarrow \pi^{*}$ of imine groups that are generally red shifted to lower energies. The new peaks appeared at wavelengths above the $500 \mathrm{~nm}$ after adding metal ion to the ligand during the studies can be attributed to $d \rightarrow \pi^{*}$ transition of the ML, ML2 and/or $\mathrm{M}_{2} \mathrm{~L}$. The shifting of ligand peaks towards lower energy on deprotonation of the chelating units can be explained by two ways: (i) the interaction of imine with a hydrogen-bond forming solvent would presumably reduce the $\mathrm{OH}$ bond strength and facilitate proton transfer to the nitrogen center favoring the formation of the ketoamine, which gives characteristic $n \rightarrow \pi^{*}$ transition at 

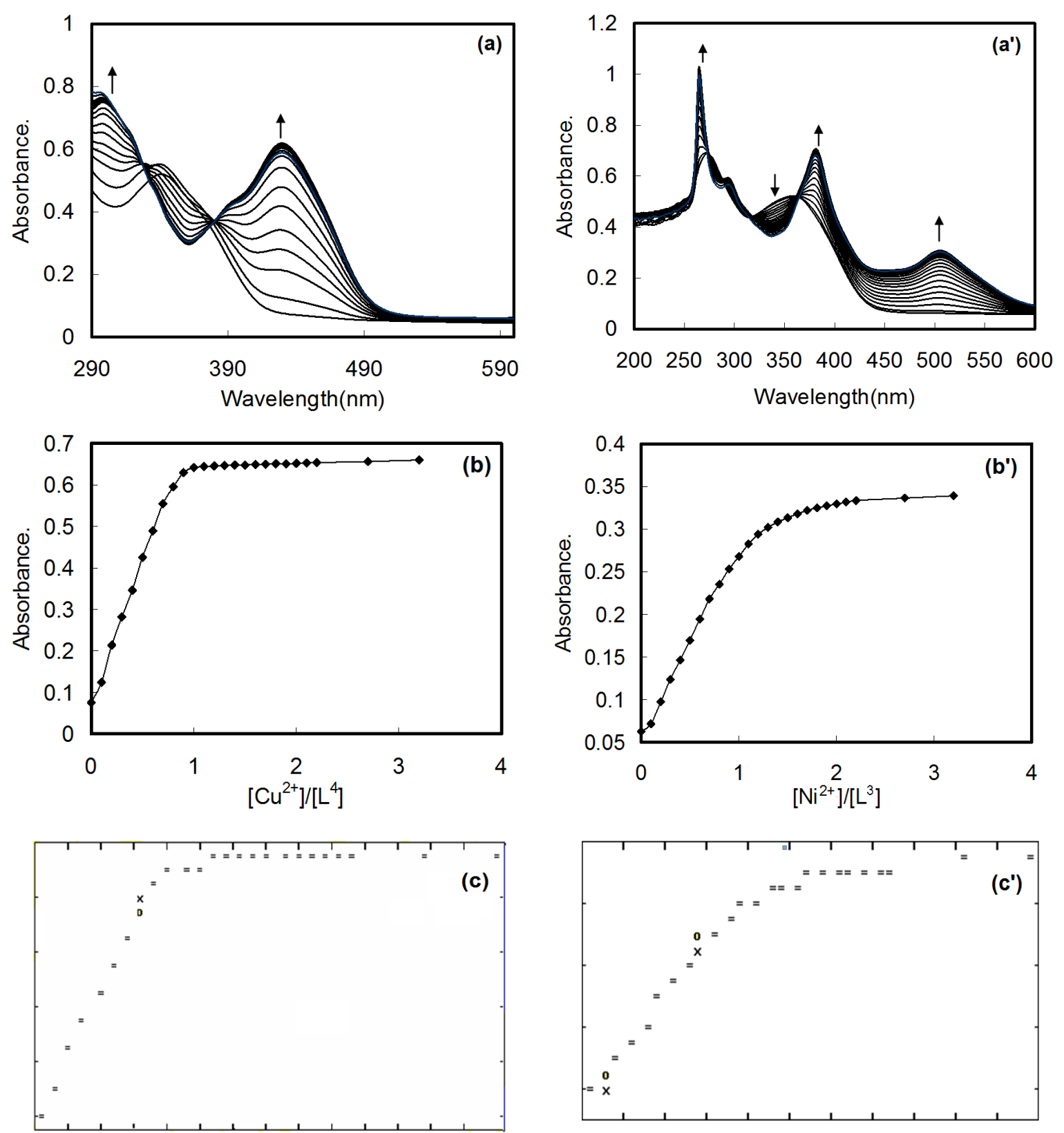

Figure 2. UV-Vis spectra for titration of $\mathrm{L}^{4}\left(3.65 \times 10^{-5} \mathrm{M}\right)$ with $\mathrm{Cu}^{2+}(\mathrm{a})$ and $\mathrm{L}^{3}\left(4.23 \times 10^{-5} \mathrm{M}\right)$ with $\mathrm{Ni}^{2+}\left(\mathrm{a}^{\prime}\right)$ ions in $\mathrm{DMF}\left(\mathrm{T}=25{ }^{\circ} \mathrm{C}, \mathrm{I}=0.05 \mathrm{M}\right.$ and $0.05 \mathrm{M}$ TEAP) and the corresponding absorbtion mole ratio plots at $431,508 \mathrm{~nm}\left(\mathrm{~b}, \mathrm{~b}^{\prime}\right)$ and corresponding curve fitting (c, $\left.\mathrm{c}^{\prime}\right)$.

longer wavelength than the corresponding enolimine; (ii) formation of phenolate ion from phenol stabilizes the $\pi \rightarrow \pi^{*}$ excited state due to charge delocalization and brings the lowest excited state closer to the highest ground state and thus permits a lower energy (longer wavelength) for transition.

In order to study the insight on the coordination mode and effect of complex formation in non-aqueous medium, the complexation was carried out spectrophotometrically in DMF using mole ratio method. In general, with the same ligands copper ion has highest and cadmium complex has the lowest stability constant as expected from Irving-William's [46], typically for $\mathrm{L}^{5}$ this order is, $\mathrm{Cd}(\mathrm{II}) \sim \operatorname{Co}(\mathrm{II})<$ $\mathrm{Ni}(\mathrm{II})<\mathrm{Cu}(\mathrm{II})>\mathrm{Zn}(\mathrm{II})$. Due to the simultaneously presence of hard oxygen atom and soft nitrogen atom in the ligands herein significant tendency for complexation with metal ions and low differences in stability constants would be expected. Ions such as Ce(III) and La(III) with high charge and low charge density have stability constant close to divalent ions.

Presence of withdrawing groups of nitro and bromide in the ligand structure reduces the complexation of ligands, while the donating group increases the stability constants of the complexes. The $\mathrm{NO}_{2}$ group in phenolic moiety $\mathrm{L}^{5}$ decreases the stability constants. This can be explained by more effective hydrogen bond of phenolic hydrogen imines by $\mathrm{NO}_{2}$ in phenolic part. Moreover, this explanation can be considered for the formation of $\mathrm{ML}_{2}$ with $\mathrm{L}^{5}$ via probably nitrogen atoms of two 

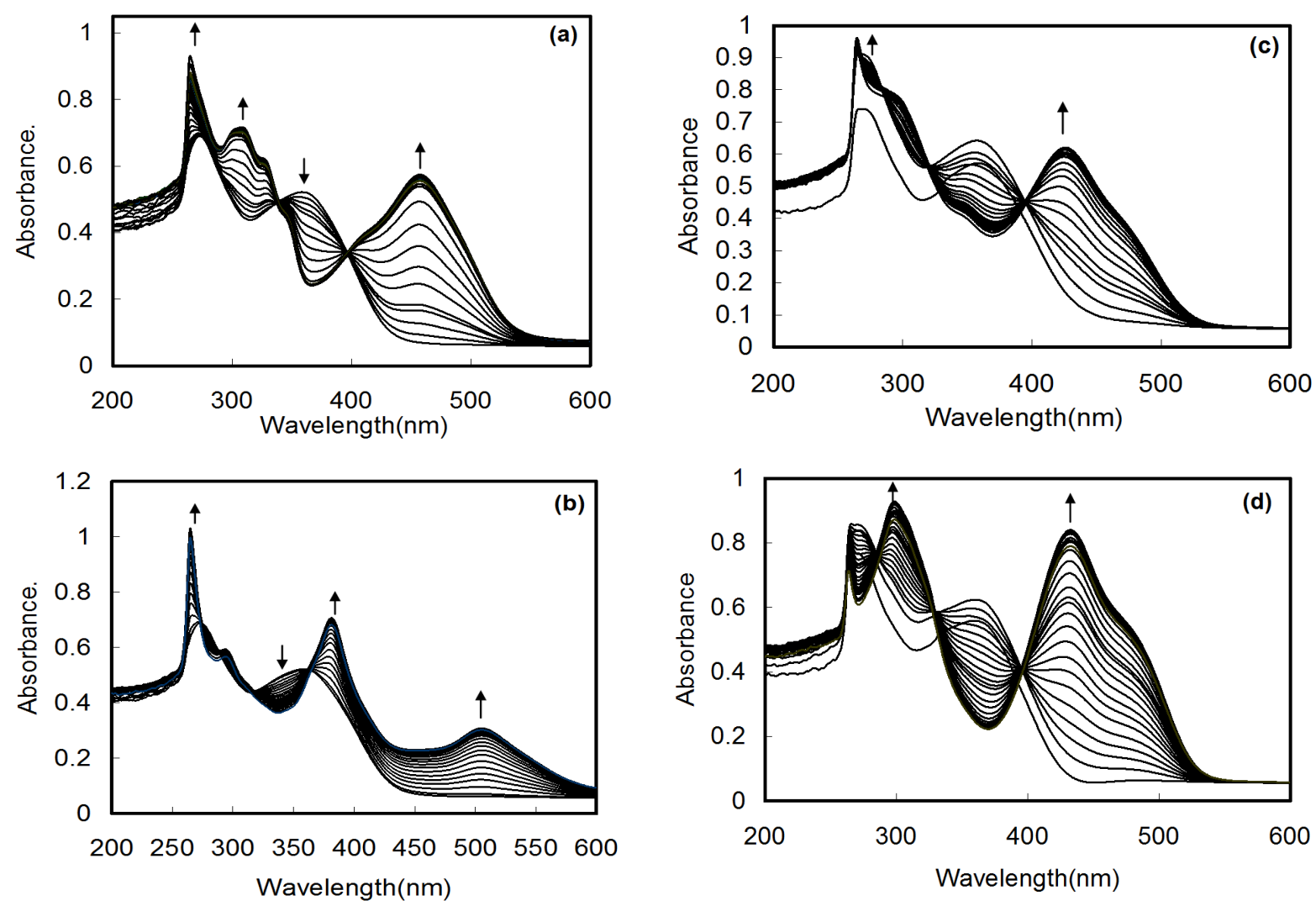

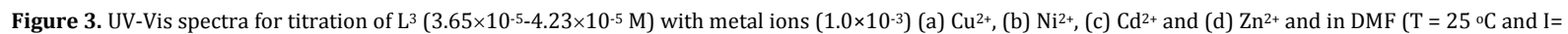
0.05 M TEAP).

ligands in a pseudo tetrahedral geometry. On the other hand, resonance toward the $\mathrm{NO}_{2}$ group of phenolic ring of $\mathrm{L}^{5}$ leads to the intra-hydrogen bond cleavage and easy rotation of one phenolic ring and therefore accepting of two metal ions such as $\mathrm{Zn}(\mathrm{II})$ to give $\mathrm{M}_{2} \mathrm{~L}$ complex. Methoxy group in 3 position of $\mathrm{L}^{1}$ leads to formation of hydrogen bonding between oxygen of methoxy with phenolic proton and reduces hydrogen bonding with nitrogen. Therefore complexation via nitrogen binding occurs and higher stability constant for complexation of metal ions with a ligand for methoxy in 3 position toward 4, 5 position could be obtained [47-49]. Methoxy in 4-position leads to higher ability of ligand for complexation [36,50,51].

The experimental electronic spectra of ligands with some metal ions between 200 and $600 \mathrm{~nm}$ are shown in Figures 1-4. Analyses of spectra using KINFIT whole at maximum wavelength give the best fit for $\mathrm{ML}, \mathrm{ML}_{2}$ or $\mathrm{M}_{2} \mathrm{~L}$ model and respective formation constants with their standard deviations are given in Tables 2 . The possibility of other types of formulations were ruled out due to the absence of any extra peak in the higher wavelengths, which was further confirmed as inclusion of additional species in the model. However, interpreting the spectra in UV-Vis region and the bathochromic shifting of ligand peaks indicate coordination of metal ion with the ligand chromophoric groups. The band at about $390 \mathrm{~nm}$ in the spectrum of the ligand associated with the $\pi \rightarrow \pi^{*}$ transition from the imine nitrogen atom is shifted significantly to higher wavelengths. The appearance of band at higher wavelengths assigned to $\pi-\pi^{*}$ of imine group with higher intensity may be attributed to coordination of imine nitrogen atoms with the metal ion upon chelation. The complexation occurs by two imine groups followed by two phenolate groups to give a uncharged hexacoordinated ML species with distorted structure and four coordinal ML spies with distorted square plan structure, where two-coordination sites are occupied by solvent molecules at trans-position. It has been shown that for a (N, O-donor) tetra dentate Schiff base ligands, the relative flexibility of this ligand allows formation of metal complexes to give a 'umbrella' or 'stepped' like geometry [52].

In general, the presence of $\mathrm{MeO}$ as a donor group in $\mathrm{L}^{1}, \mathrm{~L}^{2}$ and $\mathrm{L}^{3}$ is caused more stability of their complexes with metal ions. However $\mathrm{MeO}$ in para position to azomethine in $\mathrm{L}^{2}$ makes more stability than $\mathrm{L}^{1}$ and $\mathrm{L}^{3}$ relatively. The presence of withdrawing group in $\mathrm{L}^{4}$ and $\mathrm{L}^{5}$ is caused that these ligands have a low stability than another, withdrawing groups in 5 position can make reducing the power of hydrogen bonding and increasing the power of complex formation on the other hand the effect is caused reducing of complex formation.

\section{Conclusions}

The complexation of a series of salophnes containing the different substitutes in various positions to phenolic groups towards some metal ions has been studied in DMF through UVVis spectroscopy. The absorbance-mole ratio values in maximum wavelengths of complex or ligand have been analyzed using KINFIT program to evaluate respective stability constants and stoichiometry. The synthesized ligands form complexes with relatively high stability constants with the metal ions studied. As it is seen from Tables 2, in general, the stability constants of the most of metal ions with $\mathrm{L}^{5}$ are the lowest and with the $\mathrm{L}^{2}$ is the largest. This observation refers to the types and position of substituent such as $\mathrm{OCH}_{3}$ and $\mathrm{NO}_{2}$. 

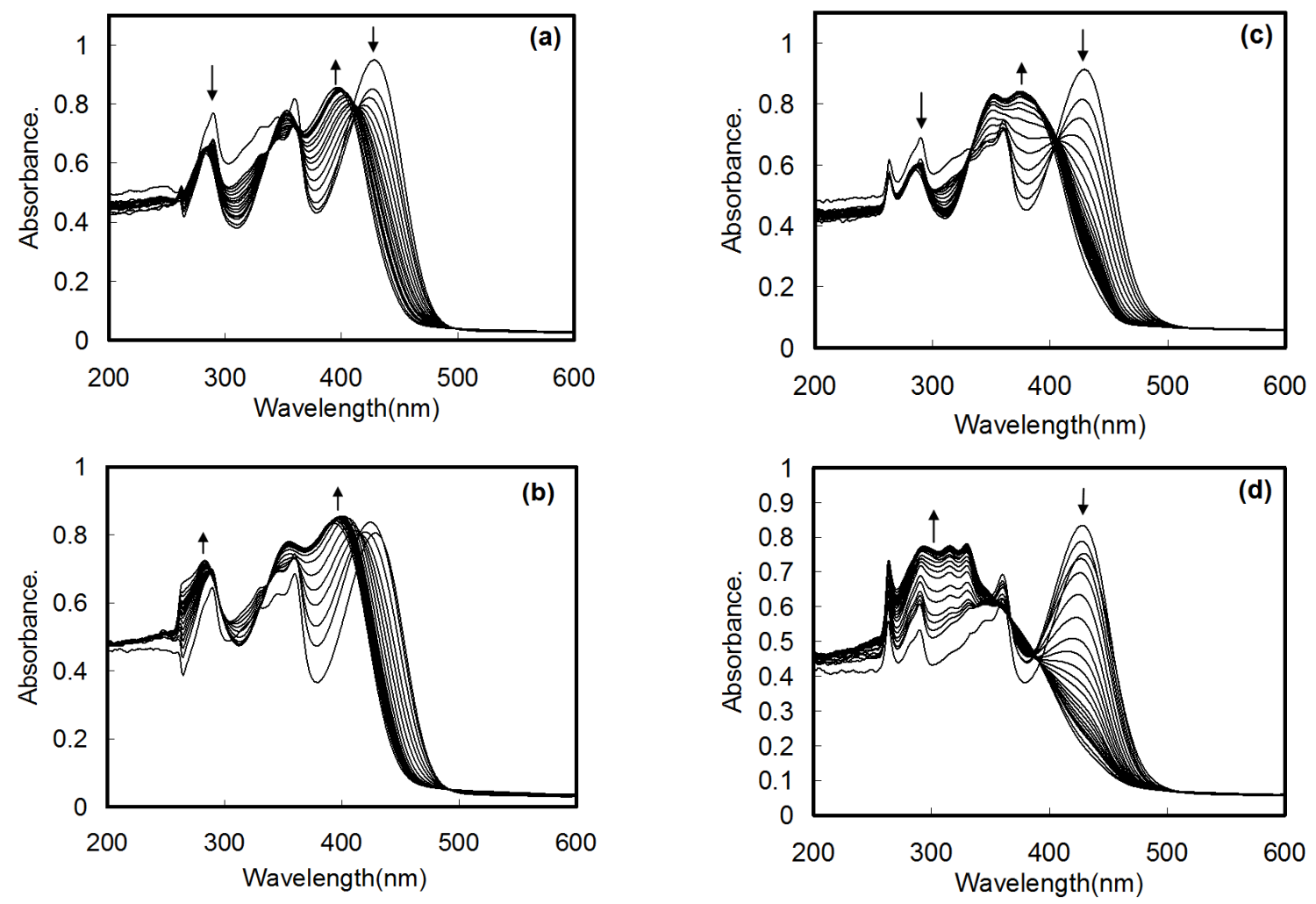

Figure 4. Uv-Vis spectra for titration of $\mathrm{L}^{5}\left(3.46 \times 10^{-5}-3.85 \times 10^{-5} \mathrm{M}\right)$ with metal ions containing $\left(1.0 \times 10^{-3}\right)(\mathrm{a}) \mathrm{Cd}^{2+}$, (b) $\mathrm{Co}^{2+}$, (c) $\mathrm{Zn}^{2+}$ and $(\mathrm{d}) \mathrm{Ce}^{3+}$ ion in $\mathrm{DMF}\left(25{ }^{\circ} \mathrm{C}\right.$ and $\mathrm{I}=0.05 \mathrm{M}$ TEAP).

Table 2. The overall stability constants of complexation between some metal ions with $\mathrm{L}^{1}, \mathrm{~L}^{2}, \mathrm{~L}^{3}, \mathrm{~L}^{4}$ and $\mathrm{L}^{5}$ at $25{ }^{\circ} \mathrm{C}$ and $0.05 \mathrm{M}$ TEAP in DMF solvent.

\begin{tabular}{|c|c|c|c|c|}
\hline Ligand & Metal ion & $\log \beta_{1}$ & $\log \beta_{2}$ & $\mathbf{M} / \mathbf{L}$ \\
\hline \multirow{7}{*}{$\mathrm{L}^{1}$} & $\mathrm{Cu}^{2+}$ & $6.08 \pm 0.07$ & $9.12 \pm 0.02$ & $1: 1 \& 1: 2$ \\
\hline & $\mathrm{Ni}^{2+}$ & $6.02 \pm 0.03$ & $8.99 \pm 0.08$ & $1: 1 \& 1: 2$ \\
\hline & $\mathrm{Co}^{2+}$ & $5.97 \pm 0.07$ & $8.95 \pm 0.02$ & $1: 1 \& 1: 2$ \\
\hline & $\mathrm{Cd}^{2+}$ & $6.20 \pm 0.10$ & $9.82 \pm 0.03$ & $1: 1 \& 1: 2$ \\
\hline & $\mathrm{Zn}^{2+}$ & $6.01 \pm 0.07$ & $8.99 \pm 0.03$ & $1: 1 \& 1: 2$ \\
\hline & $\mathrm{La}^{3+}$ & $5.99 \pm 0.04$ & $8.98 \pm 0.08$ & $1: 1 \& 1: 2$ \\
\hline & $\mathrm{Ce}^{3+}$ & $6.00 \pm 0.07$ & $9.01 \pm 0.03$ & $1: 1 \& 1: 2$ \\
\hline \multirow{7}{*}{$\mathrm{L}^{2}$} & $\mathrm{Cu}^{2+}$ & $6.53 \pm 0.10$ & - & $1: 1$ \\
\hline & $\mathrm{Ni}^{2+}$ & $5.32 \pm 0.02$ & - & $1: 1$ \\
\hline & $\mathrm{Co}^{2+}$ & $6.04 \pm 0.01$ & $9.07 \pm 0.03$ & $1: 1 \& 1: 2$ \\
\hline & $\mathrm{Cd}^{2+}$ & $5.48 \pm 0.06$ & - & $1: 1$ \\
\hline & $\mathrm{Zn}^{2+}$ & $6.21 \pm 0.11$ & - & 1:1 \\
\hline & $\mathrm{La}^{3+}$ & $6.10 \pm 0.02$ & $8.94 \pm 0.05$ & $1: 1 \& 1: 2$ \\
\hline & $\mathrm{Ce}^{3+}$ & $6.02 \pm 0.05$ & $10.07 \pm 0.03$ & $1: 1 \& 1: 2$ \\
\hline \multirow{7}{*}{$\mathrm{L}^{3}$} & $\mathrm{Cu}^{2+}$ & $5.98 \pm 0.05$ & $8.99 \pm 0.03$ & $1: 1 \& 1: 2$ \\
\hline & $\mathrm{Ni}^{2+}$ & $5.34 \pm 0.05$ & $8.42 \pm 0.03$ & $1: 1 \& 1: 2$ \\
\hline & $\mathrm{Co}^{2+}$ & $6.01 \pm 0.05$ & $9.03 \pm 0.03$ & $1: 1 \& 1: 2$ \\
\hline & $\mathrm{Cd}^{2+}$ & $6.02 \pm 0.05$ & $9.05 \pm 0.03$ & $1: 1 \& 1: 2$ \\
\hline & $\mathrm{Zn}^{2+}$ & - & $9.95 \pm 0.13$ & $2: 1$ \\
\hline & $\mathrm{La}^{3+}$ & $6.01 \pm 0.05$ & $9.04 \pm 0.03$ & $1: 1 \& 1: 2$ \\
\hline & $\mathrm{Ce}^{3+}$ & $5.95 \pm 0.05$ & $9.91 \pm 0.03$ & $1: 1 \& 1: 2$ \\
\hline \multirow{6}{*}{$\mathrm{L}^{4}$} & $\mathrm{Cu}^{2+}$ & $6.58 \pm 0.06$ & - & $1: 1$ \\
\hline & $\mathrm{Ni}^{2+}$ & $5.59 \pm 0.02$ & - & $1: 1$ \\
\hline & $\mathrm{Co}^{2+}$ & $5.31 \pm 0.14$ & - & $1: 1$ \\
\hline & $\mathrm{Cd}^{2+}$ & $3.86 \pm 0.11$ & - & $1: 1$ \\
\hline & $\mathrm{Zn}^{2+}$ & $5.73 \pm 0.30$ & - & $1: 1$ \\
\hline & $\mathrm{Ce}^{3+}$ & $6.18 \pm 0.05$ & $9.17 \pm 0.03$ & $1: 1 \& 1: 2$ \\
\hline \multirow{7}{*}{$L^{5}$} & $\mathrm{Cu}^{2+}$ & $5.06 \pm 0.05$ & $9.19 \pm 0.03$ & $1: 1 \& 1: 2$ \\
\hline & $\mathrm{Ni}^{2+}$ & $5.01 \pm 0.05$ & $7.99 \pm 0.03$ & $1: 1 \& 1: 2$ \\
\hline & $\mathrm{Co}^{2+}$ & - & $10.35 \pm 0.20$ & $1: 2$ \\
\hline & $\mathrm{Cd}^{2+}$ & $5.15 \pm 0.16$ & - & $1: 1$ \\
\hline & $\mathrm{Zn}^{2+}$ & $6.00 \pm 0.05$ & $11.01 \pm 0.03$ & $1: 1 \& 1: 2$ \\
\hline & $\mathrm{La}^{3+}$ & $5.45 \pm 0.05$ & $9.43 \pm 0.03$ & $1: 1 \& 1: 2$ \\
\hline & $\mathrm{Ce}^{3+}$ & $5.72 \pm 0.05$ & $9.97 \pm 0.03$ & $1: 1 \& 1: 2$ \\
\hline
\end{tabular}

\section{Acknowledgement}

The financial support of this work by Yasouj University is greatly acknowledged.

\section{References}

[1]. Tuzen, M. K.; Saygi, O.; Karaman, I.; Soylak, M. Food Chem. Toxicol. 2010, 48, 41-46.

[2]. Uluozlu, O. D.; Tuzen, M.; Mendil, D.; Soylak, M. Food Chem. Toxicol, 2010, 48, 1393-1398.

[3]. Tuzen, M.; Çıtak, D.; Mendil, D.; Soylak, M. Talanta, 2009, 78, 52-56.

[4]. Nishinaga, A.; Yamada, T.; Fujisawa, H.; Ishizaki, K. J. Mol. Catal. 1988 48, 249-264.

[5]. Chakraborty, H.; Paul, N.; Rahman, M. L. Trans. Met. Chem. 1994, 19, 524-526.

[6]. Sreekala, R.; Yusuff, K.; Mohammed, K. Catal (Pap Natl Symp), 1994 507-510; Chem. Abstr., 1999, 130, 115551.

[7]. Bhardwaj, C. N.; Singh, V. R. Indian J. Chem. 1994, 33A, 423-425.

[8]. Bharamagouclar, T. D.; Pujar, M. A.; Alagawadi, A. R. Curr. Sci. 1987, 56, 889-890.

[9]. Dash, B.; Mahapatra, P. K.; Panda, D.; Patnaik, J. M. J. Indian Chem. Soc. 1984, 61, 1061-1064.

[10]. Pandeya, S. N.; Sriram, D.; Nath, G.; De, C. E.; Farmaco. 1999, 54, 624628.

[11]. Mirzabdullaev, A. B.; Aslanova, D. K.; Ershov, F. I. Prep. Induktory Interferona (Imst Biol Org Khim, Tashkent USSR) 1981, 129-344; Chem Abstr, 1984, 99, 22191.

[12]. Huneck, S.; Schreiber, K.; Grimmecke, H. D. J. Plant Growth Regul. 1984, 3, 75-84.

[13]. Hadjipavlu, L.; Dimitra, J.; Geronikaki, A. Drug Des. Discovery 1998, 15 199-206.

[14]. Luo, X.; Zhao, J.; Ling, Y.; Liu, Z. Chem. Res. Chinese Univ. 2002, 18, 287289.

[15]. Parashar, R. K.; Sharma, R. C.; Mohan, G. Biol. Trace Elem. Res. 1989 $23,145-150$.

[16]. Singh, R.; Gupta, N.; Fahmi, N. Indian J. Chem. 1999, 38A, 1150-1158. 
[17]. Befta, Unsymmetrical 1:2 chromium complex dyes, Fabio (to Ciba Geigy AG), Eur. Pat. Appl. 1985, 103, 161871.

[18]. Fakhari, A. R.; Khorrami, A. R.; Naeimi, H. Talanta 2005, 66, 813-817.

[19]. Gupta, V. K.; Goyal, R. N.; Sharma, R. A. Talanta 2009, 78, 484-490.

[20]. Gupta, V. K.; Goyal, R. N.; Jain, A. K.; Sharma, R. A. Electrochim. Acta 2009, 54, 3218-3224.

[21]. Gupta, V. K.; Singh, A. K.; Pal, M. K. Anal. Chim. Acta 2008, 624, 223231.

[22]. Fathi, S. A. M.; Parinejad, M.; Yaftian, M. R. Sep. Purif. Technol. 2008, 64, 1-7.

[23]. Yoshikawa, M.; Mori, Y.; Tanigaki, M.; Egcuhi, W. Bull. Chem. Soc. Jpn. 1990, 63, 304-306.

[24]. Gupta, V. K.; Pal, M. K.; Singh, A. K. Anal. Chim. Acta 2009, 631, 161169

[25]. Shokrolahi, A.; Ghaedi, M.; Shabani, R.; Montazerozohori, M.; Chehreh, F.; Soylak, M.; Alipour, S. Food Chem. Toxicol. 2010, 48, 482-489.

[26]. Dehghan Abkenar,Sh.; Hosseini,M.; Salavati-Niasari, M. Asian J. Chem. 2008, 20, 4291-4300.

[27]. Dye, J. L.; Nicely, V. A. J. Chem. Edu. 1971, 48, 443-448.

[28]. Safavi, A.; Rastegarzadeh, S. Anal. Sci. 1999, 15, 173-175.

[29]. Martell, A. E.; Motekaitis, R. J. Determination and Use of Stability Constants, VCH,'Publishers, New York, 1992, pp. 143.

[30]. Moghimi, A.; Shokrollahi, A.; Shamsipur, M.; Aghabozorg, H.; Ranjbar, M. J. Mol. Struct 2004, 701, 49-56.

[31]. Moghimi, A.; Alizadeh, R.; Shokrollahi, A.; Aghabozorg, H.; Shamsipur, M.; Shockravi, A. Inorg. Chem. 2003, 42, 1616-1624.

[32]. Aghajani, Z.; Aghabozorg, H.; Sadr-Khanlou, E.; Shokrollahi, A.; Derki, S; Shamsipur, M. J. Iran. Chem. Soc. 2009, 6, 373-385

[33]. Shokrollahi, A.; Ghaedi, M.; Rajabi, H.R.; Niband, M.S. Spectrochim. Acta Part A 2008, 71, 655-662.

[34]. Aghabozorg, H.; Manteghi, F.; Ghadermazi, M.; Mirzaei, M.; Salimi, A.R.; Shokrollahi, A.; Derki, S.; Eshtiagh-Hosseini, H. J. Mol. Struct. 2009, 919, 381-388

[35]. Shokrollahi, A.; Ghaedi, M.; Montazerozohori, M.; Kianfar, A. H.; Ghaedi, H.; Khanjari, N.; Noshadi, S.; Joybar, S., E-J. Chem. 2011, 8, 495506.

[36]. Sarvestani, A.H.; Mohebbi, S. J. Chem. Res. 2006, 4, 257-260.

[37]. Kolthoff, I. M. J. Am. Chem. Soc. 1957, 79, 1-7.

[38]. Popov, A. I, J. M. Lehn, In coordination chemistry of macrocyclic compounds, Melson G.A. Ed.; Plenum press, New york, 1985.

[39]. Strasser, B. O.; Popov, A. I. J. Am. Chem. Soc. 1985, 107, 7921-7924.

[40]. Popov, A. I. Pure Appl. Chem. 1979, 51, 101-105.

[41]. Ben-Saber, S. M.; Maihub, A. A.; Hudere, S. S.; El-Ajaily, M. M. J. Microchem. J. 2005, 81, 191-194.

[42]. Han, H.; Ruan, W. J.; Zhao, X. J.; Hu, G. H.; Zhu, Z. A. Synth. React. Inorg. Met.-Org. Chem. 2003, 33, 1011-1023.

[43]. Sakiyan, I.; Logoglu, E.; Arslan, S.; Sari, N.; Sakiyan, N. BioMetals 2004, 17, 115-120.

[44]. Khalil, M. E.; Bashir K. A, J. Coord. Chem. 2002, 55, 681-696

[45]. Mederos, A.; Dominguez, S.; Hernandez-Molina, R.; Sanchiz J.; Brito, F. Coord. Chem. Rev. 1999, 193, 857-911.

[46]. Irving, H; Williams, R. J. P. J. Chem. Soc. 1953, 3192-3210.

[47]. Asadi, M.; Aein Jamshid, Kh.; Kyanfar, A. H. Inorg. Chim. Acta 2006, 360, 1725-1730.

[48]. Asadi, M.; Aein Jamshid, Kh.; Kyanfar, A. H. Transition Met. Chem. 2007, 32, 822-827.

[49]. Asadi, M.; Aein Jamshid, Kh.; Kyanfar, A. H.; Synth. React. Inorg. Met.Org. Chem. 2007, 37, 77-83.

[50]. Sarvestani, A. H.; Salimi, A.; Mohebbi, S.; Hallaj R. J. Chem. Res. 2005, 3, 190-193.

[51]. Jager, E. G.; Schuhmann, K.; Gorls, H. Inorg. Chim. Acta 1997, 255, 295305.

[52]. Santos, M. A.; Gaspar, M.; Amorim, M. T. Inorg. Chim. Acta 1999, 284, 20-29. 